This is a self-archived final draft version of the original article. It differs from the original in pagination and typographic detail.

This article may be used for non-commercial purposes in accordance with Wiley Terms and Conditions for Self-Archiving.

Mikkola, R., Paavilainen, E., Salminen-Tuomaala, M. \& Leikkola, P. 2018. Out-of-hospital emergency care providers' work and challenges in a changing care environment.

Scandinavian Journal of Caring Sciences 32 (1), 253-260. DOI:

http://dx.doi.org/10.1111/scs.12456

First online: 19.5.2017

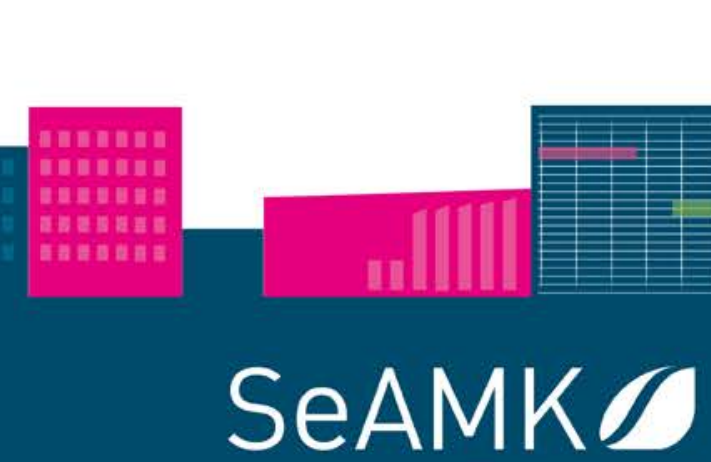

SEINÄJOEN AMMATTIKORKEAKOULU verkkolehti.seamk.fi 


\section{Out-of-hospital Emergency Care Providers' Work and Challenges in a Changing Care Environment}

\begin{tabular}{|r|r|}
\hline J ournal: & Scandinavian Journal of Caring Sciences \\
\cline { 1 - 1 } Manuscript ID & SCS-2016-0293.R1 \\
\cline { 1 - 1 } Manuscript Type: & Original Article \\
\cline { 1 - 1 } Keyword-Area of Expertise: & Emergency, Accident and Emergency, Care Givers, Paramedical Care \\
\cline { 1 - 1 } Keyword-Research Expertise: & Qualitative Approaches, Quantitative Approaches \\
\hline
\end{tabular}




\section{Page 2}

SCHOLARONE ${ }^{m}$

Manuscripts

Scandinavian Journal of Caring Sciences 


\begin{abstract}
Acutely ill patients are often treated on site instead of being transported to hospital, so wideranging professional competence is required from staff. The aim of this study was to describe and produce new information about out-of-hospital emergency care providers' competence, skills and willingness to engage in self-development activities, and to uncover challenges experienced by care providers in the midst of changing work practices. A quantitative questionnaire was sent to out-of-hospital emergency care providers ( $N=142$, response rate $53 \%$ ) of one Finnish hospital district. Data were analyzed using SPSS for Windows 22 software. Almost all respondents found their work interesting and their ability to work independently sufficient. The majority found the work meaningful. Almost $20 \%$ felt that work was dominated by constant rush, and $40 \%$, more than half of 25 -year-olds but less than $10 \%$ of over 45 -yearsolds, found the work physically straining. The majority indicated that they had a sufficient theoretical-practical basis to perform their regular duties, and more than one-third felt that they had sufficient skills to deal with multiple patient or disaster situations. Over $20 \%$ stated that they were unsure about performing new or infrequent procedures. A number of factors experienced as challenging were revealed. The results provide a basis for improving care providers' initial and further training.
\end{abstract}

Keywords Emergency medical service, emergency care provider, ambulance service, prehospital

\title{
INTRODUCTION
}

Health care is faced with ever-increasing requirements in several countries. Population growth and aging $[1,2]$ increase the workloads and demand for health services, which is also reflected in patient transport and out-of-hospital emergency care services. The continuous growth of healthcare costs has led to a search for ways of achieving savings in health services $[3,4]$ In the past, patients requiring emergency care were almost exclusively transported by ambulance to a hospital for further treatment [5]. However, many patients not requiring urgent care can be treated on site and do not necessarily need immediate hospital care [3, 6-10]. Emergency department congestion is a global problem [11]. If more patients were treated by out-of-hospit emergency care providers on site, the number of patients at emergency departments could be reduced [10] and patients in need of urgent treated more quickly.

A change in out-of-hospital emergency care providers' job description has been reported in a few countries, for example in the UK and the US [12]. Nowadays, an assessment of the situation is conducted on the basis of the patient's condition in order to identify the possibility of treating the patient on site instead of hospital [10,11, 13-16]. It has been reported that outof-hospital emergency care providers have treated patients without transportation to hospital in cases where the patient had a minor trauma, blunt injury to the head or face, or no illness or injury [10]. 
Emergency care providers respond to tasks assigned by emergency medical dispatchers [8, 12], and they are often a patient's first contact with health services. The ambulance and emergency care services are responsible for ensuring that suddenly ill or injured patients are appropriately assessed and treated on site and during transport [16]. Out-of-hospital emergency care providers' work is varied; their tasks vary on a daily basis. They have been trained to manage emergency incidents including accidents, sudden illness, falls and childbirths. Thus, care providers need to be able to deal with pressure and have wide-ranging expertise $[8,17,18]$. The work is physically and mentally demanding [19] and dominated by unpredictable situations. It is carried out in the most diverse working environments $[15,20]$ and it includes administering out-of-hospital emergency care to patients of all ages [15]. Especially incidents involving children, for example children's accidents or deaths, or administering life support to children, have been found to be stressful to care providers [21]. Training [18] and support [20] are important in ensuring that out-of-hospital emergency care staff can cope in their challenging work.

In Finland, regional hospital districts are responsible for providing emergency medical services [22]. There are two levels of ambulance service: basic life support vehicles, in which care providers monitor the patient and start simple life-saving procedures during transport, and advanced life vehicles for more sophisticated procedures carried out to secure the patient's vital functions. The crew in basic-level ambulances may consist of emergency medical technicians or practical nurses, whereas advanced emergency care vehicles are often staffed by two emergency nurses or general nurses $[23,24]$.

\begin{abstract}
AIMS
The aim of this study was to describe the experiences that nurses, hospital and ambulance attendants, emergency medical technicians and practical nurses working in out-of-hospital emergency care have of their work and of challenges related to their changing work practices. The study aimed at producing new knowledge about persons working in out-of-hospital emergency care in order to develop their basic and further training. The research questions particularly focused on the following aspects:

- How do out-of-hospital emergency care providers rate their competence and skills at emergency care work and their willingness to take part in further development and training?

- How do out-of-hospital emergency care providers experience the challenges related to their changing work practices?
\end{abstract}

\title{
METHODS
}

\section{Study design and instrument}

This study is a cross-sectional study, whose data were collected from one hospital district in Finland using the Webropol online survey software. A pilot study $(\mathrm{N}=17)$ was conducted in 
June - July 2014, and this material was combined with the data from the actual survey, carried out in September - October 2014. The overall sample size was 142 and the response rate 53\%.

A questionnaire based on previous studies and literature $[5,6,17,21]$ was developed for this study specifically. The questionnaire consisted of 8 background information questions, 70 Likert statements and two open questions. The Likert scale used seven options (fully agree, agree, somewhat agree, somewhat disagree, disagree, fully disagree, and is not part of my job). The options agree and fully agree were combined and, similarly, disagree and fully disagree combined into one category. Responses to the option "not part of my job" were classified as missing information. The statement "I am unsure about carrying out new infrequent procedures" was followed by a question, in which respondents were asked to name taskscausing uncertainty.

\section{Statistical analysis}

Data were analyzed using the SPSS (version 22) programme. First, frequency distributions, medians and means were calculated, followed by cross-tabulations to examine the distribution of variables and dependencies between them [25]. The chi-square test $\left(x^{2}\right)$ was used to assess statistical dependencies. Statistical significance was described by the $p$-value [26], with values under 0.050 indicative of a dependence or difference $[25,26]$.

\section{Ethical considerations}

The relevant research approvals as well as the assent of the South Ostrobothnia Hospital District's ethical committee to conduct the study were obtained. The study was guided by the Medical Research Act. Participation in the study was voluntary and individual responses could not be identified in the statistical printouts or analysis $[27,28]$. The study participants also had an opportunity to communicate with researchers throughout the study.

\section{RESULTS}

\section{Participants}

There was an equal number of women and men. The participants' age ranged between 19 and 58 years and their mean age was 34 years. The majority of the respondents (68\%) worked in advanced emergence care and the rest, (32\%) in basic emergency care services. Most (75\%) of the respondents had permanent employment contracts, while $25 \%$ had fixed-term contracts. The participants consisted of 86 nurses (60.6\%), 48 practical nurses (33.8\%) and 8 hospital and ambulance attendants/emergency medical technicians (5.6\%) (Table 1). More than a third of the respondents had worked in out-of-hospital emergency care less than 3 years.

\section{Out-of-hospital emergency care providers' experience of their work}

The majority of the respondents (96.5\%) felt that their work was interesting and involved 
adequate challenges (90\%). Looking at differences by age, younger respondents found their work more interesting compared to older care providers $(p=0.017)$. Similarly, advanced level care providers experienced their work as more interesting compared to basic level care providers $(p=0.016)$. A minority $(16 \%)$ reported that their work was dominated by a constant rush. The rates were $18 \%$ for men and $13 \%$ for women, respectively. However, nearly $40 \%$ of the care providers considered the work physically demanding. Slightly over half of the under 25-year-olds found the work physically demanding, whereas in the over 45 -year-olds, $8 \%$ considered their work physically demanding. In other words, older respondents found the work physically less demanding than younger respondents $(p<0.000)$. In addition, approximately $30 \%$ of the participants found their work mentally demanding (Table 2 ).

\section{Self-rated competence in out-of-hospital emergency care}

Most of the participants in the survey (82\%) considered that they possessed the skills and abilities required to perform out-of-hospital emergency care work. With regard to gender, men rated their competence slightly higher $(92 \%)$ than did women $(73 \%),(p=0.012)$. More than $90 \%$ of the respondents reported ability to quickly assess a patient's out-of-hospital emergency care needs. They felt able to work under pressure, while $84 \%$ of them also reported being able to implement treatment in rapidly changing situations. Most of the respondents (82\%) also felt they had sufficient capacity for independent decision making. Nevertheless, roughly onequarter of the care providers considered the level of responsibility for the treatment of patients as excessive. According to approximately $60 \%$ of the respondents, the work constantly required developing new capabilities due to changing work practices. This was especially true of those who had worked longer in the health service (62\%), compared to care providers with less than 3 years of work experience in health care (40\%). Most study participants reported possessing good theoretical knowledge and skills for carrying out their work; the rates were $85 \%$ for employees on permanent contracts and $69 \%$ for those on fixed-term contracts. Over one fifth of the respondents indicated that they had not received adequate induction to their current work. In regard to occupation, the majority (70\%) of hospital and ambulance attendants, emergency medical technicians and practical nurses felt that their induction had been adequate, whereas less than half of the nurses found that they had received sufficient induction $(p=0.013)$.

\section{Practical skills}

Almost $90 \%$ of the respondents felt that they had sufficient practical skills required in their work. The rates were slightly higher for employees on permanent contracts (91.5\%) than for those on fixed-term contracts (81\%). Similarly, a larger proportion of care providers with more than 1.5 years' experience of their current work, over $90 \%$, considered having adequate practical skills compared to those having worked less than 1.5 years in their current position (73\%). Those with a longer work history in their current workplace rated their overall practical 
skills as better than those with a short history in the workplace $(p=0.017)$. More than one third (36\%) of all respondents claimed to have sufficient skills for multiple patient situations or disasters. Comparing the results by age, it was found that more men (44\%) than women (28\%) claimed to have sufficient skills for multiple patient situations or disasters $(p=0.008)$. The longer the care providers' work experience, the more likely their experienced confidence: Adequate skills for multiple patient and disaster situations were reported by $51 \%$ of those with over 8 years' experience of out-of-hospital emergency care, by $38 \%$ of those with 3-8 years' experience and by $21 \%$ of those, who had worked less than 3 years in out-of-hospital emergency care services $(p<0.000)$. Almost one fourth $(23 \%)$ of the study participants stated that they were uncertain as regards new procedures or infrequent tasks. In regard to gender, women (nearly $30 \%$ ) felt slightly more uncertain about new or infrequent procedures compared to men $(20 \%),(p<0.000)$. Tasks most commonly mentioned as sources of uncertainty involved transcutaneous pacing, initiating an intra-osseous infusion, childbirths, emergency tracheostomies, opening of airways, and generally, carrying out various procedures. A further difference detected in regard to gender was than men rated their technical skills slightly higher than women ( $p=0.019)$. In men, $75 \%$ and in women, $53 \%$ reported good technical skills for the performance of various procedures. Most $(85 \%)$ respondents also indicated having good technical skills for managing the relevant equipment and tools.

\section{Self-development}

The majority (91.5\%) of the study participants wanted to develop their professional competence further. Most of them (75\%) thought that the training they had received had provided them the competence to carry out their current tasks. There was some variation between groups: In men, $86 \%$ and in women, $63 \%$ reported that their training had provided a sufficient basis for their current work. As regards occupational groups, less nurses (65\%) reported that their training had provided a sufficient basis for their current work compared to other professional groups $(89 \%),(p=0.011)$. Of all study participants, $61 \%$ planned to acquire updating and further training in the near future. There was variation in the results as regards type of employment: a majority of those with a fixed-term work contract (92\%) planned to acquire further training compared to those in with a permanent contract $(50.5 \%),(p<0.000)$. Similarly, as regards the current job level, a larger share of respondents working in basic care (70\%) planned to acquire further training in near future compared to those working advanced emergency care $(45 \%),(p=0.001)$. The care providers with less than 3 years' experience in outof-hospital care (83\%) were more interested in updating their skills or availing of further training compared to care providers with longer work history $(43 \%-53 \%)(p<0.000)$. Similar results were obtained as regards the amount of professional experience in health care. For those who had worked less than 3 years in health care, the figure was $96 \%$, whereas in the other groups the figure varied between $48 \%$ and $58 \%$. It seems that care providers with fewer years of experience working in health care were more interested in updating their skills or obtaining further training than those with more years work experience in this field $(p=0.002)$. 


\section{Challenges related to changing work practices}

When asked to rate cooperation and working community support, approximately $40 \%$ of the participants found working in a multi-professional environment challenging. As regards age, the younger respondents (under 25-year-olds, 13\%) found the multi-professional working environment more challenging than the older respondents (age groups 25 years and above, 40$50 \%),(p=0.017)$. On the other hand, those who had worked a shorter time in out-of-hospital emergency care ( $<1.5$ years, $25 \%)$, experienced working in a multi-professional environment as less challenging than those who had worked longer $(<2.5$ years, $51 \%)(p=0.002)$. Similar results were obtained as concerns experience of health care. Those who had worked a shorter time in health care ( $<3$ years, $16 \%$ ) experienced working in a multi-professional environment as less challenging compared to those who had worked a longer period ( $>8$ years, $48 \%)(p=0.014)$. The majority, $63 \%$ of the respondents, felt that co-operation with the authorities was good. Those who had worked longer in health care (>8 years, $73 \%$ ) found the cooperation smoother compared to those with a shorter work history in health care $(<3$ years, $56 \%)(p=0.010)$. Less than half of the respondents thought that cooperation with the regional hospitals was good, whereas cooperation with dispatchers proceeded smoothly according to $79 \%$ of all respondents.

Most (72\%) of the study participants felt that they had received adequate support from their colleagues. Less than half of the respondents reported having received sufficient help and advice from the emergency doctor on duty. Approximately one third of the respondents thought that they had received sufficient support from their superiors and employers.

\section{DISCUSSION}

The work of out-of-hospital emergency care providers is varied and they require extensive knowledge and skills in a wide range of nursing fields. Similar to some previous studies [12], respondents in this study found their work interesting. They felt, however, that their work was hurried and physically strenuous. Younger study participants found the work physically heavier compared to older respondents. The results might be partly explained by younger carproviders' limited work experience. Changes in work practices also bring on challenges, making it harder to cope at work. In a work life dominated by hurry, the risk of occupational injuries will increase. Previous studies have highlighted the increased risk of physical injuries among out-ofhospital emergency care providers [29, 30].

The daily tasks of out-of-hospital emergency care providers vary a great deal; they may involve basic life support, acute care of multiple seriously injured patients, major trauma cases or, for example, cardiac rhythm interpretation and assisting with childbirth. Earlier studies have reported that traumatic events and tragedies, as well as sudden transitions from calm situations to emergencies, constitute a source of stress for out-of-hospital emergency care personnel [29, 31]. Participants in this study, however, found that their work was slightly less stressful mentally than physically. Approximately a third of the respondents indicated that their 
job was mentally burdening. The finding may be connected with the fact that one fifth of the care providers felt that their work was characterized by constant rush. Out-of-hospital emergency care personnel are required to adapt to changes in treatment practices and to constantly learn new knowledge and skills [32]. In this study, too, more than half of the participants reported that their work required them to continuously develop new capabilities to meet the changing practices. The result might be partly explained by the finding that one fifth of the respondents felt that they had not received sufficient orientation to their current work. Considering that nurses have a responsible role in decision-making and in the overall emergency situation, it is especially noteworthy that more than half of them found that their orientation had been inadequate. Additional training has been found to decrease nurse vacancy rates, increase patient satisfaction and improve nurse satisfaction-decision-making, among other things [33].

Out-of-hospital emergency care workers have a duty to care for both individual patients and a greater number of patients in the most varied situations. In this study, nearly $90 \%$ of the out-ofhospital emergency care personnel reported that they had sufficient practical skills for their work. In another study [34], emergency care providers mainly assessed their clinical skills as good or excellent, although they felt less confident performing intubation and caring for gynecological patients. More than a third of the respondents in this study felt that they had sufficient skills to act in a multiple patient or disaster situation. The younger respondents in particular, and those who had worked a shorter time in out-of-hospital emergency care, experienced uncertainty in multiple patient or disaster situations. New and infrequent procedures, for example emergency tracheostomy and opening the patient's airways, were also a source of uncertainty. Similar results have been obtained earlier with regard to emergency department personnel, who confessed to fear when faced with multiple patient or major accident situations or with new tasks and rare procedures [35]. This study further revealed that almost all respondents wanted to develop their professional competence. The majority of the participants or almost all temporary employees and nearly half of the permanent contract employees, planned to acquire updating or further education.

Emergency workers must be able to work in a team and collaborate with other professional roups [36]. In this research, the respondents who had worked for a shorter time in emergency and health care found the multi-professional environment less challenging than those who had worked for a longer time in the field. Although they considered cooperation with dispatchers and authorities as flexible, less than half of the respondents regarded cooperation with regional hospitals as smooth. They reported that colleagues were the main source of support, a finding also documented in a study involving emergency department staff [35]. Emergency care providers' work is physically and mentally challenging and it involves dealing with patients' and family members' problems and suffering. Receiving support is essential, so that these professionals can thrive in their demanding work. 


\section{LIMITATIONS}

This study was conducted within a single hospital district, which serves a population of nearly 200,000 in 20 municipalities. The hospital district area has two hospitals. The results of the study cannot be generalized, but they can be applied both in Finland and internationally; containing universal features, they can help understand and develop out-of-hospital emergency care services.

\section{Implications for out-of-hospital emergency care providers}

Research on the work of out-of-hospital emergency care providers is important as practices and job descriptions change to meet current challenges. Respondents in this study found their work meaningful but strenuous, especially physically. Most of them rated their practical and theoretical competence as good, although they also experienced uncertainty as regards new or infrequent procedures. Based on this study, it is possible to develop basic and updating training for out-of-hospital emergency care providers to improve their competence in out-of-hospital emergency care. The results can also be useful when developing emergency care providers' working conditions to improve job satisfaction and coping at work.

\section{CONCLUSIONS}

The results of this study indicate that out-of-hospital emergency care providers are satisfied with their jobs, although changing medical practices bring new professional requirements. The care providers typically face challenges and uncertainty in their work. Challenges reported in this study involved new and rarely performed procedures as well as multiple patient or major accident situations. Still, the respondents assessed their practical skills and work capacity as good. Most study participants wanted to develop their professional competence further and planned to acquire updating or further training in the near future. 


\section{References}

1. Lowthian JA, Cameron PA, Stoelwinder JU, Curtis A, Cooke MW, McNeil JJ. Increasing utilisation of emergency ambulances. Austr Health Rev 2011; 35(1):63-69.

2. Platts-Mills T, Leacock B, Cabanas J, Shofer F, McLean S. Emergency medical services use by the elderly: analysis of a Statewide Database. Prehosp Emerg Care 2010; 14:329-333.

3. Cooper S, Grant J. New and emerging roles on out of hospital emergency care: A review of the international literature. Int Emerg Nurs 2009; 17(2): 90-8.

4. Weinick RM, Burns RM, Mehrotha A. How many emergency department visits could be managed at urgent centers and retail clinics? Health Aff 2010; 29(9): 1630-6.

5. Squires JP, Mason S. Developing alternative ambulance response schemes: analysis of attitudes, barriers, and change. Emerg Med J 2004;21:724-7.

6. Bigham BL, Kennedy SM, Drennan I, Morrison L. Expanding paramedic scope of practice in the community: a systematic review of the literature. Prehosp Emerg Care 2013;17: 361-72.

7.Cooper S, Barrett S, Black S, Evans C, Real C, Williams S, Wright B. The emerging role of the emergency care practitioner. Emerg Med J 2004;21: 614-8.

8. Evans R, McGovern R, Birch J, Newbury-Birch, D. Which extended paramedic skills are making impact in emergency care and can related to the UK paramedic system? A systematic review of the literature. Emerg Med J 2014;31: 594-603

9. Mason S, Knowles E, Colwell B, Dixon S, Wardrope J, Gorringe R, Snooks H, Perrin J, Nicholl J. Effectiveness of paramedic practitioners in attending 999 calls from elderly people on the community: cluster randomized controlled trial. BMJ 2007; 335: 919-22.

10. Snooks HA, Dale J, Hartley-Sharpe C, Halter M. On-scene alternatives for emergency ambulance crews attending patients who do not need to travel to the accident and emergency department: a review of the literature. Emerg Med J 2004; 21: 212-5.

11. Kilcoyne $M$ \& Dowling $M$. Working in an overcrowded accident and emergency department: nurses' narratives. Aust J Adv Nurs 2007; 25(2): 21-7. 
12. Woollard M. The role of the paramedic practitioner in the UK. J Emerg Prim Health Care 2006; $4: 1-9$

13. Halter M, Vernon S, Snooks H, Porter A, Close J, Moore F, Porsz S. Complexity of the 33 decision-making process of ambulance staff for assessment and referral of older people who have fallen: a qualitative study. Emerg Med J 2011; 28:44-50.

14. Leikkola P, Mikkola R, Salminen-Tuomaala M, Paavilainen E. Non-conveyance of patients: challenges to decision-making in emergency care. Clin Nurs Stud 20164 (4), 31-9. DOI:

10.5430/cns.v4n4p31

15. Mason S, Knowles E, Freeman J, Snooks H. Safety of paramedics with extended skills. Acad Emerg Med 2008;15: 607-12.

16. Newgard CD, Nelson MJ, Kampp M, Saha S, Zive D, Schmidt T, Daya M, Jui J, Wittwer L, Warden C, Sahni R, Stevens M, Gorman K, Koenig K, Gubler D, Rosteck P, Lee J, Hedges JR. Outof-hospital decision-making and factors influencing the regional distribution of injured patients in a trauma system. J Trauma 2011; 70(6): 1345-53.

17. Salminen-Tuomaala M, Leikkola $P$, Paavilainen E. Patient and staff safety incidents and near misses in out-of-hospital emergency care. Emerg Med 2014; 4:5.

18. Von Wyl T, Zuercher M, Amsler F, Walter B, Ummenhofer W. Technical and non-technical skills can be reliably assessed during paramedic stimulation training. Acta Anaesthesiol Scand 2009; 53:121-7.

19. Hansen CD, Rasmussen K, Kyed M, Nielsen KJ, Andersen JH. Physical and psychosocial work environment factors and their association with health outcomes in Danish ambulance personnel - a cross-sectional study. BMC Public Health 2012; 12: 534

20. Bigham BL, Jensen JL, Tavares W, Drennan IR, Saleem H, Dainty KN, Munro G. Paramedic self-reported exposure to violence in the emergency medical services (EMS) workplace: a mixed-methods cross-sectional survey. Prehosp Emerg Care 2014; 18: 489-94.

21. Prati G, Pietrantoni L, Cicognani E. Coping strategies and collective efficacy as mediators between stress appraisal and quality of life among rescue workers. Int J Stress Manag 2011; $18(2), 181-95$.

22. Ministry of Social Affairs and Health in Finland. Health Care Act $1326 / 2010$ [English

Ttranslation from Finnish], http://www.finlex.fi/en/laki/kaannokset/2010/en20101326 
23. Ministry of Social Affairs and Health in Finland. Asetus ensihoitopalvelusta 340/2011 [Decree on Prehospital Emergency Care, in Finnish and Swedish], http://www.finlex.fi/fi/laki/alkup/2011/20110340

24. Itä-Uudenmaan pelastuslaitos [Itä Eastern Uusimaa Emergency Services Department] Ensihoitojärjestelmä [Emergency Medical Services, in Finnish].2011, http://www.iupela.fi/palvelut/ensihoito/ensihoitojarjestelma accessed 16/1/2017

25. Plichta, S.B., Garzon, L.S. Statistics for Nursing and Allied Health. 2009, Wolters Kluwer Health/Lippincott Williams \& Wilkins, Philadelphia, 5, 26-28, 85.

26. Schmidt, N.A., Brown, J.M. Evidence-Based Practice for Nurses. 2014, Jones \& Bartlett Learning, Boston, 345-347, 377-378.

27. Fouka G, Mantzorou M. What are the major ethical issues in conducting research? Is there a conflict between the research ethics and the nature of nursing? Health Sci J 2011; 5(1), 3-14.

28. Giordano J, O’Reilly M, Taylor H \& Dogra N. Confidentially and autonomy: the challenge(s) of offering research participants a choice of disclosing their identity. Qual Health Res 2007; 17(2), 264-75.

29. Nirel N, Goldwag R, Feigenberg Zvi, Abadi D, Halpern P. Stress, work overload, burnout, and satisfaction among paramedics in Israel. Prehosp Disaster Med 2009; 53:121-7.

30. Roberts $\mathrm{MH}$, Sim MR, Black O, Smith P. Occupational injury risk among ambulance officers and paramedics compared with other healthcare workers' compensation claims from 2003 to 2012. Occup Environ Med 2015; 72(7), 489-95.

31. Johnsson A, Segesten K, Mattsson B. Post-traumatic stress among Swedish ambulance personnel. Emerg Med J 2003; 20:79-84.

32. Paakkonen H. The contemporary and future clinical skills of emergency department nurses, 2008. Kuopio University publications E. Social sciences 163.

33. Kooker, B.M., Kamikawa, C. Successful strategies to improve RN retention and patient outcomes in a large medical centre in Hawaii. J Clin Nurs 2011;20: 34-9.

34. Salminen-Tuomaala, M., Leikkola, P., Mikkola., R., Paavilainen, E. Workers' clinical skills at out-of-hospital emergency care. Emerg Med 2015; 5(6), 1-6.

35. Mikkola, R. Hoitohenkilökunnan kokema pelko ja selviytymiskeinot ensiapupoliklinikoilla 33 [Experiences of Fear and coping strategies among staff in emergency departments. Model for coping with fear. Abstract in English]. Academic dissertation. Acta Universitatis Tamperensis 1829. 2013. 
36. Cooper S, O'Carroll J, Jenkin A, Badger B. Collaborative practices in unscheduled emergency care: role and impact of the emergency care practitioner - quantitative findings. Emerg Med J 2007; 24(9): 630-3. 


\section{Page 15}

Table 1. Demographic data on respondents 


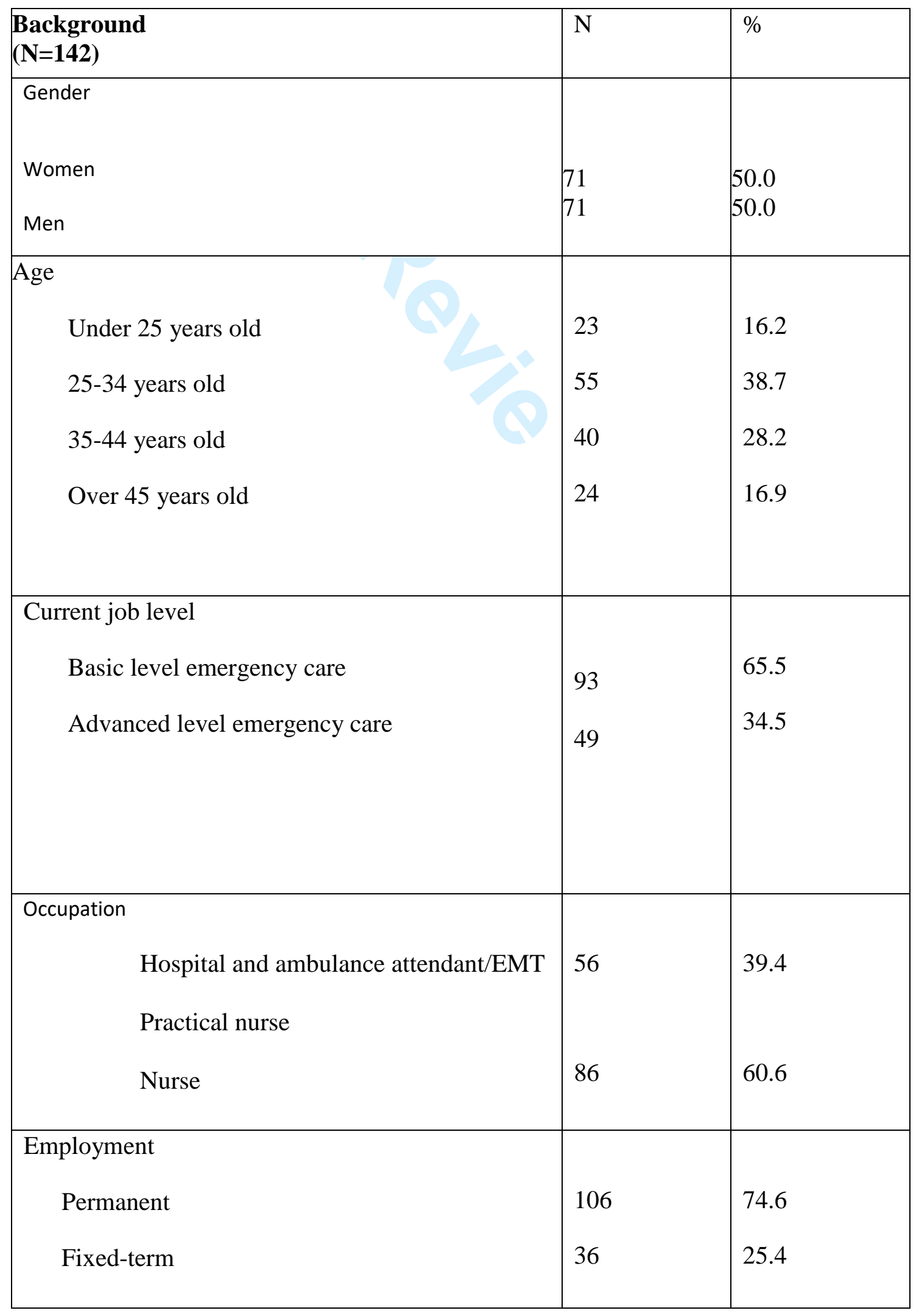




\section{Page 17}

\begin{tabular}{|c|l|l|}
\hline $\begin{array}{l}\text { Years employed in current work }(\mathrm{N}=141) \\
\text { Under } 1.5 \text { years }\end{array}$ & 33 & 23.4 \\
\hline $\begin{array}{l}\text { 1.5 years }-2.4 \text { years } \\
\text { 2.5 or more years }\end{array}$ & 36 & 53.9 \\
\hline Years employed in emergency care & 22.7 \\
Under 3 years & 52 & 36.6 \\
3-8 years & 45 & 31.7 \\
Over 8 years & 45 & 31.7 \\
\hline
\end{tabular}




\section{Page 18}

Table 2. Emergency care providers' experiences of their work 


\begin{tabular}{|c|c|c|c|c|}
\hline $\begin{array}{l}\text { EMERGENCY CARE PROVIDERS’ } \\
\text { RATINGS OF THEIR WORK (N=142) }\end{array}$ & Mean & $\begin{array}{l}\text { Standard } \\
\text { Deviation }\end{array}$ & $\begin{array}{l}\text { Lowest } \\
\text { value * }\end{array}$ & $\begin{array}{l}\text { Highest } \\
\text { value * }\end{array}$ \\
\hline $\begin{array}{l}\text { Experience of work } \\
\text { My work is interesting }\end{array}$ & 3.95 & 4.00 & 1 & 4 \\
\hline There are sufficient challenges at work & 3.89 & 4.00 & 2 & 4 \\
\hline The work is dominated by constant rush & 2.54 & 3.00 & 1 & 4 \\
\hline My work is physically strenuous & 3.05 & 3.00 & 1 & 4 \\
\hline The work is mentally taxing & 2.86 & 3.00 & 1 & 4 \\
\hline $\begin{array}{l}\text { Self-rated competence } \\
\text { I possess sufficient capability for } \\
\text { independent work }\end{array}$ & 3.80 & 4.00 & 1 & 4 \\
\hline $\begin{array}{l}\text { I can quickly assess the patient’s urgent } \\
\text { care needs }\end{array}$ & 3.92 & 4.00 & 3 & 4 \\
\hline I can work under pressure & 3.95 & 4.00 & 3 & 4 \\
\hline $\begin{array}{l}\text { I have received } \\
\text { sufficient duties }\end{array}$ & 3.24 & 4.00 & 1 & 4 \\
\hline $\begin{array}{l}\text { I have sufficient capability to implement } \\
\text { care quickly in changing circumstances }\end{array}$ & 3.83 & 4.00 & 2 & 4 \\
\hline $\begin{array}{l}\text { My ability to make independent } \\
\text { decisions is sufficient }\end{array}$ & 3.79 & 4.00 & 1 & 4 \\
\hline
\end{tabular}




\begin{tabular}{|c|c|c|c|c|}
\hline $\begin{array}{l}\text { I feel that my responsibility level for } \\
\text { patient care is too high. }\end{array}$ & 1.93 & 2.00 & 1 & 4 \\
\hline $\begin{array}{l}\text { New capabilities are continuously required } \\
\text { as work practices change }\end{array}$ & 3.44 & 4.00 & 1 & 4 \\
\hline $\begin{array}{l}\text { My theoretical knowledge and skills are } \\
\text { sufficient for performing my duties }\end{array}$ & 3.80 & 4.00 & 2 & 4 \\
\hline $\begin{array}{l}\text { Practical Skills } \\
\text { I have good technical skills for performing } \\
\text { the procedures }\end{array}$ & 3.63 & 4.00 & 2 & 4 \\
\hline $\begin{array}{l}\text { I have good skills in } \\
\text { the use of equipment } \\
\text { and instruments }\end{array}$ & 3.82 & 4.00 & 2 & 4 \\
\hline I have sufficient practical skills & 3.87 & 4.00 & 2 & 4 \\
\hline $\begin{array}{l}\text { I have sufficient skills to operate in a } \\
\text { multiple patient or disaster situation }\end{array}$ & 3.05 & 3.00 & 1 & 4 \\
\hline $\begin{array}{l}\text { I am unsure about carrying out new or } \\
\text { infrequent procedures }\end{array}$ & 2.65 & 3.00 & 1 & 4 \\
\hline $\begin{array}{l}\text { Self-Development } \\
\text { I want to develop my professional } \\
\text { competence continuously }\end{array}$ & 3.90 & & 1 & 4 \\
\hline
\end{tabular}




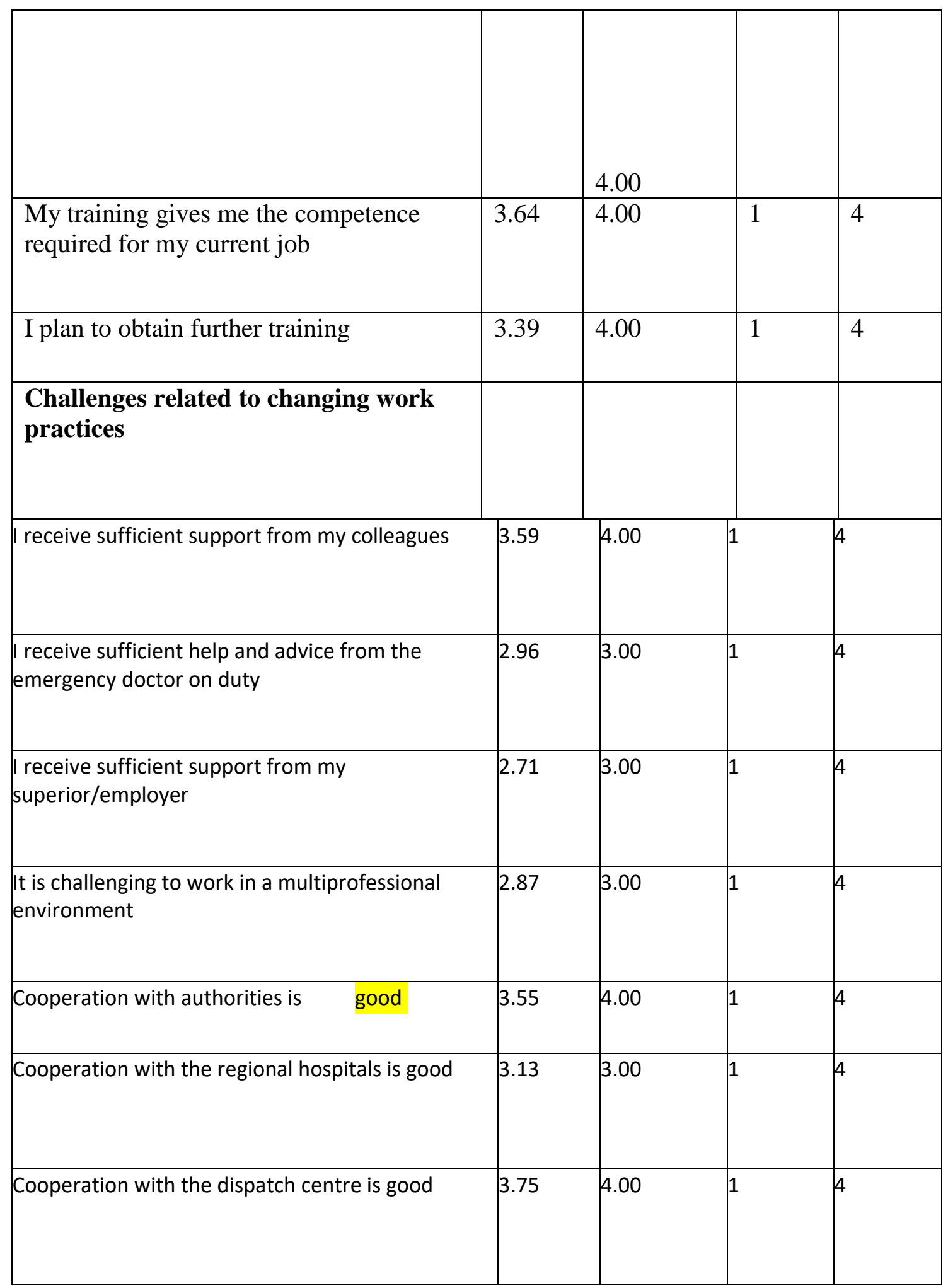

* 1 = disagree or fully disagree, $2=$ somewhat disagree, $3=$ somewhat agree, $4=$ agree or fully agree 